\title{
SAM (self-assembled monolayer)-based Photocatalytic Chip from Immobilized Polytriazoles $\dagger$
}

\author{
Periyamuthu Ramar, ${ }^{\text {a,b }}$ Venkatraman Raghavendra, ${ }^{\mathrm{b}, \mathrm{c}}$ and Debasis Samanta*a,b

Polymer Science \& Technology division, CSIR-CLRI, Adyar, Chennai-600020, India. E-Mail: debasis@clri.res.in Fax: + 91-44-24911589; Tel: +91-44-
24422059.
Academy of Scientific and Innovative Research, Rafi Marg, New Delhi, India
Inorganic and Physical Chemistry Department and Centre for High Computing, CSIR-CLRI, Adyar, Chennai-600020

A third-generation photocatalytic chip can play an essential role in sunlight-driven dye degradation, hydrogen production, etc. Choice of active substances, as well as fabrication methods, are important for practical utilization of the materials. In this paper, we reported devising a photocatalytic chip using immobilized polytriazoles of diketopyrrolopyrrole (DPP) and zinc oxide for the first time. For immobilization, the self-assembled monolayer (SAM) formation techniques were utilized with superior results. Different methods confirmed efficient immobilization and high grafting density for the SAM technique. Computational models suggested favorable energy parameters for the active materials. Photocatalysis was studied for the degradation of multiple polluting dyes under standard environmental conditions using immobilized polytriazoles.

\section{INTRODUCTION}

Photocatalysts offer a convenient method of chemical transformations driven by photon sources like natural sunlight. $^{1,2}$ Examples include chemical degradation of polluting dyes ${ }^{3}$ production of hydrogen from water ${ }^{4}$ methane production from acetic acid ${ }^{5}$ etc. Immobilization of polymers is an integral part of research for developing photocatalyst in the form of a chip. ${ }^{6}$

Polymers can be immobilized to various surfaces by different coating methods. ${ }^{7}$ For example, they can be drop-casted on a surface from fairly dilute solutions. ${ }^{8}$ However, it may not produce a uniform layer in some instances. ${ }^{9}$ Spin-coating can create a more uniform layer, although maintaining the proper orientation of an active functional group is often challenging. ${ }^{10}$

${ }^{11}$ Proper orientation of the molecules can be controlled in a better way by using Langmuir-Blodgett film (LB film) formation technique, where amphiphilic molecules are assembled on surfaces using a special instrumentation technique. ${ }^{12} \mathrm{LB}$ films are often fragile in nature and limited to specific substrates. ${ }^{13}$ In this context, controlled decorations using self-assembled monolayer (SAM) formation techniques ${ }^{14}$ can provide more reliable and durable surfaces. In the recent review articles, we highlighted various aspects of SAM formation techniques ${ }^{15}$ particularly, SAM-driven "graft from", "graft to", "graft through" techniques. ${ }^{16}$ Such controlled decorations can facilitate the enhancement of device performances. Formation of self-assembled onolayer (SAM) with silane molecules particularly attracted several attentions as they form covalently attached monolayer on relevant surfaces, like, silicon, indium tin oxide, glass etc. Further, the SAM formation on surfaces allows fine-tuning of several surface properties like wettability, conductivity, etc. Such controlled decorations can facilitate the enhancement of device performances. In photovoltaic devices, the SAM layers with small organic molecules can tune the power conversion efficiency. For example, L. Yang and others demonstrated the formation of highly dense poly(3-methylthiophene) selfassembled monolayer to Indium tin oxide surfaces and used as a new hole transport layer in bulk heterojunction polymer solar cells. ${ }^{17}$ They noted that those SAM-based hole-transport layers provide higher power conversion efficiency, superior stability in various solvents. Along the same line, Chiu et. al. reported that the SAM-modified device has an improvement in the charge carrier mobility and short circuit current, for better device performances. ${ }^{18}$ Considering those advantages of SAMbased materials in device performances, preparation of SAM of designer polymers for improved efficacy, particularly as a photocatalytic chip was undertaken as the main objective of the study.

Another issue related to the performance of a device is the design of polymer ${ }^{19}$ to be immobilized as SAM. Other research groups and we reported that diketopyrrolopyrrole (DPP), ${ }^{20}$ coupled with various aromatic moieties play an important role in controlling multiple parameters related to device performances. ${ }^{21}$ While in most cases, different moieties were connected with the double bond or triple bond by employing Suzuki or Sonogashira coupling, ${ }^{22}$ several years back, we reported that triazole as the connector could provide interesting systems for their unique optoelectronic properties. ${ }^{21}$ Hence, herein, we report immobilization of a novel DPP-based click polymer to the surface by graft to SAM formation technique. Further, since the solubility is an important issue for the products after click polymerization, ${ }^{23}$ we introduced long alkyl chains to both monomers for improving the solubility.

Although many photocatalytic processes ${ }^{24}, 25$ like dye degradation, production of hydrogen from water ${ }^{4}$, or methane production from acetic acid have some similarities in initiation mechanisms, we chose to study in detail the photocatalytic degradation of generally polluting dyes using SAM of DPPbased click polymer as the initial model. This is particularly important considering recent interests in the removal of polluting dyes ${ }^{26}$ by using third-generation photocatalysts in which the immobilized substrates are used as catalysts. ${ }^{25,27}$

Although very recently we reported devising a photocatalytic chip by coating the materials of choice for bulk heterojunction solar cell devices, to the best of our knowledge, this is the first detailed study on devising SAM-based photocatalytic chip using designer click polymer. 
Scheme 1. "Click" polymerizations on diketopyrrolopyrrole (DPP) -based M1 monomer, followed by immobilization using self-assembled monolayer (SAM) formation technique: "Graft to" method. Inset picture: GPC chromatogram of click polymers P1 and P2.

\section{RESULTS AND DISCUSSION}

\subsection{IMMOBILIZATION OF DPP-BASED POLYMER BY SAM FORMATION}

Scheme 1 depicts the general strategy of immobilization of DPPbased click polymer to surface by SAM formation techniques. In brief, alkyne functionalized DPP-based polytriazoles were prepared first using click polymerization. Those polymers were immobilized to surfaces using "graft to" method in presence of a suitable catalyst. Results on synthesis, characterization of polymers, and immobilization techniques have been presented below.

\subsubsection{Synthesis and Optical Properties of the polymers:}

Dialkynated DPP monomer (M1), diazido monomer (M2), and phenylazide (compound S7) were synthesized using modified literature procedures as described in the ESI section S2 (scheme S1, S2, and S3) and spectral data of that synthesized compounds were provided in ESI figure $\mathrm{S} 1$ to $\mathrm{S} 10 .{ }^{28-30}$ Initially, we attempted the model click reaction (scheme 2) of dialkynated DPP monomer (M1) by reacting with phenyazide in THF - water mixture at $50^{\circ} \mathrm{C}$ in the presence of $\mathrm{CuSO}_{4} \cdot 5 \mathrm{H}_{2} \mathrm{O}$ and Na-ascorbate. After 22 hours, the product was recovered and purified by column chromatography and characterized by FT-IR and ${ }^{1} \mathrm{H}$ NMR spectroscopy techniques. In the FT-IR spectrum; after click reaction, the disappearance of azide peak was observed at $2100 \mathrm{~cm}^{-1}$, and in ${ }^{1} \mathrm{H}$ NMR spectrum, the new characteristic peak appeared at $7.8 \mathrm{ppm}$ for triazole ring $\mathrm{C}-\mathrm{H}$ proton, which reflected the success of the click reaction on monomer 1 molecule (shown in figure S10 in ESI) ${ }^{5}$. Detailed procedure for the synthesis has been given below in the Experimental section (section 3.2.1).

After establishing the condition for click reaction on a model substrate, click polymerization reactions were performed using two different catalyst systems ( $\mathrm{CuI}$ for $\mathrm{P} 1$ polymer and $\mathrm{CuSO}_{4} \cdot 5 \mathrm{H}_{2} \mathrm{O} / \mathrm{Na}-$ ascorbate for $\mathrm{P} 2$ polymer) separately maintaining reaction condition at $50^{\circ} \mathrm{C}$ for 48 hours in the presence of base $e^{6,7}$. In both cases, after completion of polymerization, the characteristic color change from red to dark violet was observed. The crude product was purified by soxhlet extraction with different solvents sequentially, like methanol, acetone, diethyl ether, and chloroform. Finally, we obtained the click polymers in the chloroform fraction. The elaborated synthetic procedure is given in the experimental part. The formation of click polymers in both cases was confirmed by FTIR, NMR, and GPC. As observed by FT-IR spectroscopy in figure $1 \mathrm{~A}$, the near-complete disappearance of peaks at around $2100 \mathrm{~cm}^{-1}$ corresponding to azide and alkyne group stretching indicated the success of click polymerization. A small residual peak at $2100 \mathrm{~cm}^{-1}$ indicated the presence of alkyne / azide end groups in the polymer chains.

Further, the formation of polymers was confirmed by ${ }^{1} \mathrm{H}$ NMR spectroscopy (figure 1B and S11 in ESI). In ${ }^{1} \mathrm{H}$ NMR spectrum, the new peak at 7.63-7.85 ppm confirmed the formation of triazole ring and the disappearance of the peak indicated near completion of the reaction. Two C-H protons signals of thiophene rings were observed at $8.90-9.15 \mathrm{ppm}$ and at $7.65-7.25 \mathrm{ppm}$ as a broad signal. All other characteristic aliphatic $\mathrm{CH}_{2}$ and $\mathrm{CH}_{3}$ proton signals were also 
observed. As observed from GPC, the $\mathrm{M}_{\mathrm{n}}$ values of polymers are $7435 \mathrm{~g} / \mathrm{mol}$ and $5967 \mathrm{~g} / \mathrm{mol}$, respectively for P1 and P2, indicating different degrees of polymerization while using $\mathrm{CuI}$ catalyst (scheme 1 , insert picture). The absorption and emission spectral analysis of polymers were taken in $\mathrm{CHCl}_{3}$ solution and thin film form, as shown in figure 1C. Dialkynated DPP monomer showed maximum absorption wavelength at $586 \mathrm{~nm}$, which is attributed to $\pi-\pi^{*}$ electronic transition of diketopyrrolopyrrole units ${ }^{5}$. After polymerization, similar types of absorption $(596 \mathrm{~nm})$ were observed, indicating the difference in extension of conjugation during polymerization. From the onset value of absorption wavelength, we observed the optical bandgap values of M1, P1, and P2 were 1.73 $\mathrm{eV}, 1.72 \mathrm{eV}$ and $1.75 \mathrm{eV}$, respectively (table 1). In fluorescence spectra, the maximum emission wavelength of DPP monomer was shown at $602 \mathrm{~nm}$, and click polymers were shown at $612 \mathrm{~nm}$, revealing a good fluorescence activity with intense red emission ${ }^{5}$. The geometry, electronic structure and frontier orbital energy levels
(FMOs) (HOMO and LUMO) of click polymer molecules with one repeating unit were studied by using density functional theory calculations. We calculated the energy level values of ground (LUMO) and excited state (HOMO) with respect to the click polymer electronic structure as $-2.52 \mathrm{eV}$ and $-4.81 \mathrm{eV}$, respectively, with theoretical bandgap values of $2.29 \mathrm{eV}$ (figure 1D). These results reveal that, the theoretical bandgap values have shown good agreement with experimental values. Further, it was observed from computational models that both HOMO and LUMO were located in the diketopyrrolopyrrole (DPP) moiety and it can facilitate the intermolecular charge transfer transition between DPP and quinol units of click polymer ${ }^{8,9}$. The electrochemical properties of monomers and polymers were studied by cyclic voltammetry to find the HOMO, LUMO and band-gap values $\left(\mathrm{E}_{\mathrm{g}}\right)$ as shown in figure $2 \mathrm{~A}$ and table 1. The bandgap values of M1, M2, P1, and P2 were 1.79, $1.64,1.51$, and $1.62 \mathrm{eV}$, respectively.

Figure 1. (A) FT-IR spectra of monomers and polymer P2; (B) ${ }^{1} \mathrm{H}$ NMR spectrum of click polymer P2; (C) combined UV-Vis absorption and emission spectra of M1 monomer and polymers (P1 and P2) in solution $\left(\mathrm{CHCl}_{3}\right)$; (D) Topologies of frontier molecular orbital diagram of analog of click polymer structure with one repeating unit;

Thermal analysis of monomer and polymers were studied by TGA and DSC measurements with the heating rate at $10{ }^{\circ} \mathrm{C}$ per minute (figure 2C, 2D and ESI figure S6). The TGA data shows the DPP monomer has more stability of up to $391{ }^{\circ} \mathrm{C}$ plausibly due to the $\pi-\pi$ stacking between the DPP molecules. The onset decomposition temperature of click polymer $\mathrm{P} 1$ and $\mathrm{P} 2$ has $169^{\circ} \mathrm{C}$ and $175^{\circ} \mathrm{C}$ respectively, plausibly due to the slow breaking of alkyl chains from polymers. The glass transition temperature of polymers was analyzed by DSC instrument and the $\mathrm{T}_{\mathrm{g}}$ value of click polymer was found to be at around $55^{\circ} \mathrm{C}-60^{\circ} \mathrm{C}$. The relatively low values of glass transition temperature can be attributed to the presence of more alkyl chains and more flexibility between the polymer chains ${ }^{10}$.

The crystalline nature of monomers and polymers was studied by powder XRD at two theta ranges of 3-80 degrees as shown in figure 2B. The DPP monomer (M1) showed three different sharp peaks at $4.60,9.28$, and 18.69 degrees at two theta values ${ }^{11}$. The 
corresponding $\mathrm{d}$ spacing values, mentioned in figure $2 \mathrm{~B}$, indicated the DPP monomer (M1) is highly crystalline in nature. The click polymer P2 showed two broad XRD patterns with two theta values at 3.83 and 21.30 degrees. It was indicating the highly amorphous nature and the two planes of diffraction in the polymer microstructures due to the presence of $\pi-\pi$ stacking in between DPP cores. The P1 polymer shows four peaks at 4.71, 9.80, 15.11, and 20.73 degrees of two theta values.

Figure 2. (A) Cyclic voltammetry graph and (B) XRD patterns of monomers (M1 and M2) and polymers (P1 and P2); Thermal analysis data (C) TGA and (D) DSC curves of M1 monomer and click polymers (P1 and P2)

\begin{tabular}{|c|ccc|c|cr|}
\hline Code & $\begin{array}{c}\mathrm{E}_{\text {ox }} \\
\text { onset }\end{array}$ & $\begin{array}{c}\text { HOMO } \\
(\mathrm{eV})\end{array}$ & $\begin{array}{c}\mathrm{E}_{\text {red }} \\
\text { onset }\end{array}$ & $\begin{array}{c}\text { LUMO } \\
(\mathrm{eV})\end{array}$ & $\begin{array}{c}\mathrm{E}_{\mathrm{g}(\mathrm{elc})} \\
(\mathrm{eV})\end{array}$ & $\begin{array}{c}\mathrm{E}_{\mathrm{g} \text { (opt) }} \\
\mathrm{eV}\end{array}$ \\
\hline M1 & 1.037 & -5.437 & -0.758 & -3.642 & 1.795 & 1.73 \\
\hline M2 & 1.506 & -5.906 & -0.138 & -4.262 & 1.644 & - \\
\hline P1 & 0.851 & -5.251 & -0.662 & -3.738 & 1.513 & 1.72 \\
\hline P2 & 0.970 & -5.37 & -0.652 & -3.748 & 1.622 & 1.75 \\
\hline
\end{tabular}

Table 1: HOMO, LUMO and Bandgap values (optical and electrochemical) of monomers (M1 \& M2) and polymers (P1 \& P2) from CV analysis.

2.1.2. Preparation and characterization of click polymer functionalized surfaces by "graft to" method

Since the above-mentioned polymer has alkyne as an end functional group, it can be directly clicked to azide functionalized surfaces unlike the strategy used by other research groups where end alkyne groups have been incorporated separately ${ }^{12}$. For surface functionalization, we first synthesized 3-azidopropyltrimethoxy silane from 3-chloropropyltrimethoxy silane in optimum condition following the previous literature procedure (ESI reaction scheme S4 and figure S12). Next, the glass surfaces $(2 \mathrm{~cm} \times 2 \mathrm{~cm}$ square slides) were treated with piranha solution at $90^{\circ} \mathrm{C}$ for 1 hour for making the free hydroxyl groups on surfaces. For the formation of azide functionalized glass surfaces (SAM surface), the hydroxylated surfaces were reacted with 3-azidopropyltrimethoxysilane in toluene medium at $100{ }^{\circ} \mathrm{C}$ for 2 hours. After the completion of the reaction, the slides were washed with toluene and methanol. Azide functionalized SAM were characterized by ATR-IR spectroscopy where the characteristic peaks were observed at $2095 \mathrm{~cm}^{-1}$ and $2870 \mathrm{~cm}^{-1}$ corresponding to the $\mathrm{N}_{3}$ and aliphatic $\mathrm{CH}_{2}$ stretching frequency respectively (figure $3 \mathrm{~A}$ ). Graft to click reaction on the azide-functionalized surface was successfully carried out by copperbased catalyst, as described in experimental section ${ }^{31,32}$ It was initially confirmed by FT-IR and XPS analysis as shown in figures 3A and 3B. In ATR-IR, the disappearance of the characteristic peak of azide at $2095 \mathrm{~cm}^{-1}$ and the appearance of new polymer 
characteristic peaks at $1654 \mathrm{~cm}^{-1}, 2850 \mathrm{~cm}^{-1}$, and $2925 \mathrm{~cm}^{-1}$ was observed (Figures 3A).

The success of the "graft to" click reaction on the polymerfunctionalized surface was further confirmed by XPS analysis, the survey scan spectrum of the "graft to polymer" surface was shown in Figure 3B. Generally, for the XPS analysis of azide-functionalized SAM surfaces, three kinds of nitrogen signals were observed at 401 $\mathrm{eV}\left(-\underline{\mathrm{N}}=\mathrm{N}^{+}=\mathrm{N}^{-}\right), 402 \mathrm{eV}\left(-\mathrm{N}=\underline{\mathrm{N}^{+}}=\mathrm{N}^{-}\right)$and $403 \mathrm{eV}\left(-\mathrm{N}=\mathrm{N}^{+}=\underline{\mathrm{N}^{-}}\right)$due to the presence of environmentally three different types of $\mathrm{N}$ atoms, reported in the literature, while after polymer functionalization in the
XPS spectrum of "graft to polymer" surfaces, the disappearance of azide characteristic peak at $403 \mathrm{eV}\left(-\mathrm{N}=\mathrm{N}^{+}=\underline{\mathrm{N}^{-}}\right)$was observed, and the other $\mathrm{N}$ 1s peaks for amide and tertiary amine groups have appeared between $396-403 \mathrm{eV}(4.09 \%)$, it was attributed to the presence of triazole ring and diketopyrrolopyrrole (DPP) moieties in the polymer backbones. ${ }^{33}$ Moreover, the other characteristic peaks of polymer functionalized surfaces like $\mathrm{C}(1 \mathrm{~s}), \mathrm{Si}(2 \mathrm{p}), \mathrm{O}(1 \mathrm{~s})$ and $\mathrm{S}(2 \mathrm{p})$ peaks were also present in the range between 281.2-289.3 eV (39.60\%), 99.4-105.1 eV (19.44\%), 529.5-536.4 eV (31.19\%) and $159.8-164.1 \mathrm{eV}(0.09 \%)$ respectively (Figure 3B).

Figure 3. (A) ATR-IR spectra of non-functionalized surface, azide-functionalized surface, and polymer-functionalized surface; (B) XPS survey spectrum of polymer- functionalized surface; (C) Water droplet images and contact angle values of pristine glass and functionalized surfaces; High-resolution SEM images of (D) polymer-functionalized surface ("graft to" method) and (E) polymer drop-casted on the surface

Those XPS results reveal that the "click" polymer was successfully grafted on the glass surface through 3-azidopropyltrimethoxysilane SAM anchoring molecules by click reaction. Further, we studied the in-depth analysis of individual scan spectrum of each peak (C 1s, N 1 s, Si 2 p, and $\mathrm{O} 1 \mathrm{~s}$ ) by deconvolution method ${ }^{34,35}$ to understand the chemical modification between inorganic $\mathrm{SiO}_{2}$ glass substrate and organic polymer through 3-azidopropyltrimethoxysilane SAM anchoring molecules and the data were provided in figure 4 . As depicted in figure $4 \mathrm{~A}$, the deconvoluted $\mathrm{C} 1 \mathrm{~s}$ signals of polymerfunctionalized surfaces showed the typical four kinds of peaks appeared at $283.4 \mathrm{eV}, 284.0 \mathrm{eV}, 285.1 \mathrm{eV}$, and $287.2 \mathrm{eV}$ correspond to the binding energy of carbon (1s) regions with a different electronic environment of $\underline{\mathrm{C}}-\mathrm{C}$ (aliphatic chain), $\underline{\mathrm{C}}=\mathrm{C}$ (aromatic ring), $\underline{\mathrm{C}}=\mathrm{O}$ (cyclic amide), and $\underline{\mathrm{C}}-\mathrm{O}$ (ether) groups respectively, present in the click polymer backbone of "Graft to polymer" surface. The binding energy of $\underline{\mathrm{C}}-\mathrm{O}$ and $\underline{\mathrm{C}}=\mathrm{O}$ 1s electrons possess higher than the $\underline{\mathrm{C}}-\mathrm{C}$ and $\underline{\mathrm{C}}=\mathrm{C}$ elements due to the more electron density character present in the $\mathrm{C}=\mathrm{O}$ and $\mathrm{C}-\mathrm{O}$ groups compared to the $\mathrm{C}=\mathrm{C}$ and $\mathrm{C}-\mathrm{C}$ bonds. The deconvoluted peaks of $\mathrm{N} 1 \mathrm{~s}$ element for "graft to polymer" surfaces were described in figure $4 \mathrm{~B}$. The polymer grafted surfaces containing one type of N (1s) atom in DPP unit and two types of $\mathrm{N}(1 \mathrm{~s})$ atom in triazole unit, attributed to the successful grafting of the click polymers on glass surfaces through click reaction. The corresponding N 1s peaks were observed at $398.1 \mathrm{eV}$, 
$400.1 \mathrm{eV}$, and $401.3 \mathrm{eV}$ respectively represented as $-\mathrm{N}-\mathrm{C}=\mathrm{O}$ (cyclic amide), $-\underline{\mathrm{N}}=\underline{\mathrm{N}}-$ (triazole), and $-\underline{\mathrm{N}}-\mathrm{N}=\mathrm{N}$ (triazole) groups in figure 4 B. Moreover, the small characteristic residual peak was appeared at $403 \mathrm{eV}\left(-\mathrm{N}=\mathrm{N}^{+}=\underline{\mathrm{N}^{-}}\right)$, indicating the presence of unreacted azide groups in polymer grafted surfaces. Figures $4 \mathrm{C}$ and $4 \mathrm{D}$ typically showed the distinct deconvoluted peaks for $\mathrm{Si}(2 \mathrm{p})$ and $\mathrm{O}(1 \mathrm{~s})$ of an inorganic substrate $\left(\mathrm{SiO}_{2}\right.$ glass), SAM unit, and organic "click" polymer layer present in the "graft to polymer" surfaces. In the multiplex spectra of $\mathrm{Si}(2 \mathrm{p})$ elements, we observed the characteristic peak of $\mathrm{Si}(2 \mathrm{p})$ at $100.4 \mathrm{eV}$ indicating the O-Si-C bond formed successfully, between the glass substrate and SAM molecules through silane-oxygen coupling reaction, since the click polymer was grafted at the head group of SAM layer on the glass surfaces. In addition, along with $\mathrm{Si}-\mathrm{C}$ peak, the other $\mathrm{Si} 2 \mathrm{p}$ signals belonging to the $\underline{\mathrm{Si}}-\mathrm{O}-\mathrm{Si}$ and $\underline{\mathrm{Si}}-\mathrm{O}-\mathrm{H}$ groups in the glass and $\mathrm{SAM}$ unit also were present at $102.5 \mathrm{eV}$ and $103.1 \mathrm{eV}$ respectively. The deconvoluted $\mathrm{O}$ 1s peaks of "graft to polymer" surfaces were described in figure $4 \mathrm{D}$. The two typical characteristic O 1s elements for polymer backbones of "graft to polymer" surfaces have appeared at $530.4 \mathrm{eV}$ and 534.2 $\mathrm{eV}$ correspond to the carbonyl $(\mathrm{C}=\underline{\mathrm{O}})$ and ether $(\mathrm{C}-\underline{\mathrm{O}})$ groups respectively. However, the presence of other broad two peaks at $531.6 \mathrm{eV}$ and $532.5 \mathrm{eV}$, indicates the O 1s element signals of Si- $\underline{\mathrm{O}}-\mathrm{H}$ and Si-O-Si groups in "graft to polymer" surfaces. The deconvoluted XPS spectra of individual elements (C 1s, Si 2p, N 1s, and O 1s) reveal clearly that the polymer functionalization was successfully happened on SAM-glass surfaces through the "graft to" immobilization method.

Figure 4. XPS multiplex spectra of Polymer-functionalized surfaces after deconvolution: (A) C 1s; (B) N 1s; (C) Si 2p and (D) O 1s elements

2.2. Surface property characterization of azide-functionalized surface (SAM) and polymer-functionalized surfaces

The surface properties and surface morphologies were studied by water contact angle measurement, scanning electron microscopy, fluorescence microscopy, ellipsometry, and atomic force microscopy. As observed from ellipsometry, the thickness of polymer-functionalized surfaces and drop-casted surfaces were 90 $\mathrm{nm}$ and $110 \mathrm{~nm}$ respectively, which is more than the generally observed thickness of azide-functionalized surface $(\mathrm{SAM})^{7}$. Ellipsometric thickness measurements at different places revealed the formation of dense polymer brushes for polymer-functionalized surfaces ("graft to" method). The grafting density of "graft to polymer" surfaces were calculated using previous literature report by XPS, ellipsometry and GPC analysis of click polymer and polymer functionalized surfaces using the following equation: $\sigma=\square \rho \mathrm{N}_{\mathrm{A}} /$ $M_{w}$ where $\sigma$ is grafting density, $\rho$ is the density of the click polymer, $\square$ is the thickness of polymer grafted surfaces, $M_{n}$ is the number average molecular weight of click polymer and $\mathrm{N}_{\mathrm{A}}$ is the Avogadro's number. The surface thickness, $\mathrm{M}_{\mathrm{w}}$, and density values were found to be $90 \mathrm{~nm}, 28522 \mathrm{~g} / \mathrm{mol}$, and $1.1 \mathrm{~g} / \mathrm{cm}^{3}$ (Density of polythiophenebased polymer obtained from literature report) respectively. The grafting density of "graft to polymer" surfaces was found to be 2 
chains per $\mathrm{nm}^{2}$, indicating the dense coverage of click polymer on "graft to polymer" surfaces. ${ }^{33}$

The contact angle measurement data revealed that the drop-casted surface $\left(115 \pm 1^{\circ}\right)$ has more contact angle value than polymerfunctionalized surfaces $\left(90 \pm 1^{\circ}\right)$, which may be attributed to more roughness of the surface (figure $3 \mathrm{C}$ ). As a control, the blank surface showed the contact angle value of $30 \pm 1^{\circ}$ due to the presence of more hydroxyl groups and high smoothness. When 3azidopropyltrimethoxy silane group has been introduced on the surface by SAM formation, the hydrophobicity was increases slightly up to $57 \pm 1^{\circ}$ (SAM glass surface), attributed to the anchoring of azido alkyl chains on the surfaces (figure $3 \mathrm{C}$ ). As we mentioned above, the click polymers have a fluorescent property (emission wavelength is $612 \mathrm{~nm}$ in the visible region), so we have checked the fluorescent nature of surfaces (after and before grafting) by fluorescence microscopy in $40 \mathrm{X}$ magnifications with excitation at $550 \mathrm{~nm}$ (showed in figure 5A-C). The fluorescence microscopic images revealed that blank and azide-functionalized glass surfaces did not emit any fluorescent color at $550 \mathrm{~nm}$ excitation. The polymer immobilized surfaces ("graft to" and drop-casted) showed strong red emission. But in polymer-functionalized ("graft to" method) surfaces, emission occurs more evenly compared to drop-casted surfaces presumably due to a more orderly nature (figure $5 \mathrm{~B}$, and $5 \mathrm{C})$.

The surface morphologies and roughness profiles analyses of polymer thin films were studied by FESEM and AFM instruments. From the FESEM microscopic pictures of surfaces, (Figure 3D and $3 \mathrm{E})$ we observed the "graft to" method provided smoother surfaces compared to drop-casted surfaces. This was also corroborated by AFM analysis. The AFM topographic images of azidefunctionalized surface (SAM), polymer-functionalized surface, and drop-casted surfaces were presented in Figure 5D-F. For azidefunctionalized (SAM) surface, a non-feature morphology with a smoother surface (RMS roughness is $2.98 \mathrm{~nm}$ ) was observed. On the other hand, the polymer-drop-casted surfaces exhibited the crosslinked fibrillar ribbon structures with aggregated form (surface roughness is $12.95 \mathrm{~nm}$ ), plausibly due to the tendency of DPP click polymer to form the self-assembled structures when drop cast on surfaces as reported by $\mathrm{xi}$ et al, which showed fibrillar ribbon morphology. ${ }^{36}$ The polymer-functionalized surfaces also showed the clear dispersed fibrillar morphology with more features (surface roughness is $8.43 \mathrm{~nm}$ ), possibly due to the self-assembly of the DPP polymer backbone chains through $\pi-\pi$ stacking interactions in 'Graft to' functionalization.

Figure 5. fluorescence microscope images of (A) azide-functionalized surface, B) polymer-functionalized surface ("graft to" method) and (C) polymer dropcasted on the surface; Atomic force microscope topography images of (D) azide-functionalized surface, (E) polymer-functionalized surface ("graft to" method), and (F) polymer drop-casted on the surface.

\subsection{Preparation and characterization of $\mathrm{ZnO}$ and click polymer sensitized $\mathrm{ZnO}$ photocatalyst}

Synthesis of $\mathrm{ZnO}$ particles from zinc acetate dihydrate and sodium hydroxide was performed under optimum conditions and the solid particles were dried at $120{ }^{\circ} \mathrm{C}$ for 24 hours under vacuum ${ }^{14}$. The polymer sensitization of $\mathrm{ZnO}$ semiconductors was performed by making the composites of $\mathrm{ZnO}$ with $1 \mathrm{wt} \%$ of polymer (P2). Briefly, in a $100 \mathrm{~mL}$ single neck round bottom flask, $500 \mathrm{mg}$ of $\mathrm{ZnO}$ was dispersed in $50 \mathrm{~mL}$ of ethanol with sonication. Simultaneously prepared the polymer $(5 \mathrm{mg})$ solution in $5 \mathrm{~mL}$ of tetrahydrofuran. The polymer solution was added drop-wise into $\mathrm{ZnO}$ dispersion followed by 2 hours of stirring vigorously. The solvents were evaporated and finally bluish-white solid was obtained after drying. (480 mg). 
The pristine $\mathrm{ZnO}$ and polymer sensitized $\mathrm{ZnO}$ catalysts (polymer$\mathrm{ZnO}$ ) were characterized by FT-IR, UV-Vis DRS, UV-fluorescence, $\mathrm{XRD}$, and SEM analysis (provided in ESI). The formation of $\mathrm{ZnO}$ was confirmed by FT-IR spectrum (see in ESI figure S13) and it has characteristic peaks at $430 \mathrm{~cm}^{-1}$ attributed to the $\mathrm{Zn}-\mathrm{O}$ bond stretching frequency. In the case of polymer- $\mathrm{ZnO}$, the peaks were observed at $1750 \mathrm{~cm}^{-1}$. The peaks between 2950-3010 $\mathrm{cm}^{-1}$ corresponds to the amide $\mathrm{C}=\mathrm{O}$ bond and $\mathrm{C}-\mathrm{H}$ bond (aromatic and aliphatic) stretching frequency of click polymer. From solid-state UV DRS spectroscopy (ESI figure S14 A and S14 B) we obtained the bandgap value of pristine $\mathrm{ZnO}$ and click polymer (P2) at $3.10 \mathrm{eV}$ and $1.55 \mathrm{eV}$ respectively which belongs to their onset absorption wavelength. After polymer incorporation, the bandgap energy did not change significantly due to the non-covalent interaction between polymers and $\mathrm{ZnO}$. In the composite of polymer and $\mathrm{ZnO}$, broadening of absorption band between $400-800 \mathrm{~nm}$ was observed. The photoluminescence spectra of zinc oxide or P2-zinc oxide were obtained from ethanol at an excitation wavelength of $350 \mathrm{~nm}$. In the case of $\mathrm{ZnO}$ (ESI figure S15), four bands in the ranges of 380 to 453 $\mathrm{nm}$ were noticed. The band at $380 \mathrm{~nm}$ may be attributed to near band edge (NBE) emission of zinc oxide, which was slightly shifted to $384 \mathrm{~nm}$ in the composites. Slight shifting of other emission bands was also observed in the nanocomposites. However, increases in the fluorescence intensity from $\mathrm{P} 1-\mathrm{ZnO}$ to $\mathrm{P} 2-\mathrm{ZnO}$ (compared with $\mathrm{ZnO}$ bands) are high possibly because of the electron transfer between polymer and $\mathrm{ZnO}$. XRD was performed for $\mathrm{ZnO}$ and the composites to study the crystallinity (figure S16). For $\mathrm{ZnO}$, crystalline peaks were observed as several sharp peaks in the range of $31-76$ degrees in line with reported values to indicate good amounts of crystallinity. The crystallite size of Zinc oxide is at around $37 \mathrm{~nm}$ and for polymer P2 - Zinc oxide composite it was observed at around $28 \mathrm{~nm}$, plausibly because of physical adsorption, which can help to improve photocatalytic efficiency. In the P2-ZnO XRD pattern, a broad peak between 15 to 35 degrees can be attributed to the presence of polymer. Further, dynamic light scattering (DLS) was used to analyze the sizes of particles (figure S17 in ESI), which showed sizes of $\mathrm{ZnO}$ and $\mathrm{P} 2-\mathrm{ZnO}$ particles were in the ranges of $473.8 \mathrm{~nm}$ and 472.5 respectively. The surface morphology was studied by scanning electron microscopy (SEM), (in ESI figure S18) to show that the $\mathrm{ZnO}$ particles have irregular shape morphology due to more agglomeration. In the case of $\mathrm{P} 2-\mathrm{ZnO}$, images showed the presence of a polymer matrix that can prevent agglomeration.

\subsection{Photocatalytic dye degradation study evaluation}

Photocatalytic dye degradation studies were undertaken separately using click polymers synthesized in solution, as well as the polymer functionalized surfaces, particularly for comparison. First, to evaluate the photocatalytic efficiency, we prepared the composite catalysts $(\mathrm{P} 2-\mathrm{ZnO})$ from $\mathrm{ZnO}$ and click polymer (P2). For making thin-film catalysts, either $\mathrm{ZnO}$ was drop-casted on polymer functionalized surfaces (abbreviated as 'Graft to polymer'- $\mathrm{ZnO}$ ) or already prepared $\mathrm{P} 2-\mathrm{ZnO}$ nanocomposites were drop-cast on the glass surface (abbreviated as $\mathrm{P} 2-\mathrm{ZnO}$ film). $\mathrm{ZnO}$ alone was also drop cast separately to make the $\mathrm{ZnO}$ film. For comparison and a better understanding of photocatalysis under different conditions, we performed the photocatalytic degradation studies of rhodaminB $(\mathrm{RhB})$ and Methylene blue (MB) dyes by different catalysts like $\mathrm{ZnO}$ powder, $\mathrm{P} 2-\mathrm{ZnO}$ powder, $\mathrm{ZnO}$ film, P2-ZnO film, and "Graft to polymer"-ZnO films under natural sunlight. Different experimental conditions were used to understand (i) the effect of the initial concentration of dye, and (ii) the effect of irradiation time. The detailed experimental setup for the dye degradation procedure was described in ESI. ${ }^{37}$

In the composites of diketopyrrolopyrrole conjugated polymers with $\mathrm{ZnO}(\mathrm{P} 2-\mathrm{ZnO})$, the polymer can be strongly bound on the $\mathrm{ZnO}$ surfaces due to having the different heteroatoms (like $\mathrm{S}, \mathrm{N}$, and $\mathrm{O}$ ) in polymer backbones. Since the click polymer have a moderately low bandgap $(1.7 \mathrm{eV})$ with a broad range of absorption $(450-800 \mathrm{~nm})$, it can facilitate to act as a photosensitizer for $\mathrm{ZnO}$ with wide bandgaps. On the other hand, for preparing the film photocatalysts, we obtained photosensitizer film by drop-casting the very thin layer of $\mathrm{ZnO}$ particles on polymer functionalized surfaces ("Graft to polymer"$\mathrm{ZnO}$ ). This was done by keeping in mind that the possible mechanism of photocatalytic degradation involves the polymer molecules absorbing a greater number of photons (because of a broad range of absorption) The high electron transfer property of polymers can facilitate the transfer of electrons (in LUMO of polymer) to LUMO of $\mathrm{ZnO}$. Then the electrons and holes can react with $\mathrm{O}_{2}$ and $\mathrm{H}_{2} \mathrm{O}$ respectively in dye solution to form $\mathrm{O}_{2}{ }^{-} \cdot$ and $\mathrm{OH} \cdot$ radicals. These active radical species can be used to degrade the dye molecules (figure 8).

2.4.1. Photocatalytic degradation of $\mathrm{RhB}$ and $\mathrm{MB}$ dyes using $\mathrm{ZnO}$ powder, $\mathrm{P} 2-\mathrm{ZnO}$ composite, $\mathrm{ZnO}$ films, and $\mathrm{P} 2-\mathrm{ZnO}$ films drop-casted) under sunlight irradiation

Figure 6(A) and ESI table S1 show the effect of the concentration of dye content on dye degradation. Interestingly, $\mathrm{ZnO}$ catalyst $(20 \mathrm{mg})$ offered around $25 \%$ dye removal in $12 \mathrm{ppm}$ concentration but while in the case of $\mathrm{P} 2-\mathrm{ZnO}$ composites, effective dye degradation was $77 \%$ in the same condition, indicating that the photosensitization occurs when the light was irradiated on the composites system during the photocatalytic dye degradation. On the other hand, the film photocatalysts showed high catalytic efficiency for $\mathrm{ZnO}$ film at $43 \%$ and for P2-ZnO film (drop-casted) at around $88 \%$ compared to their powder form catalysts, which may be attributed to an increase in the surface area of catalysts covered by dye solution while making films. To calculate the rate of the reaction of photocatalytic degradation, we have performed photocatalysis in different time intervals of irradiation. The efficiency was achieved by using P2$\mathrm{ZnO}$ film at around $99 \%$ dye removal in $180 \mathrm{~min}$ (shown in figure $6 \mathrm{~B}$ and table $\mathrm{S} 3$ ). We obtained the rate constant values at $0.004 \mathrm{~min}^{-}$ 1, $0.016 \mathrm{~min}^{-1}, 0.007 \mathrm{~min}^{-1}$ and $0.021 \mathrm{~min}^{-1}$ for $\mathrm{ZnO}, \mathrm{P} 2-\mathrm{ZnO}, \mathrm{ZnO}$ film, $\mathrm{P} 2-\mathrm{ZnO}$ film catalysts respectively. These results reveal that the rate of the reaction values with $\mathrm{P} 2-\mathrm{ZnO}$ film catalyst increased five times compared to bare $\mathrm{ZnO}$ catalyst indicating that the diketopyrrolopyrrole conjugated polymer plays an important role in photocatalysis (figure. 6C and table S5). The UV-Vis spectra of the solution show the gradual decrease in the absorption values during a different time of irradiation (Figure 6D). The pictorial images of dye solution (after and before irradiation) also indicate the near-complete degradation in 3 hours. Further, we studied the photocatalytic activities of prepared $\mathrm{P} 2-\mathrm{ZnO}$ composites by studying the degradation of methylene blue dye under natural sunlight by varying the initial concentration of dye solution $(5 \mathrm{ppm}, 10 \mathrm{ppm}, 15 \mathrm{ppm}$, $20 \mathrm{ppm}, 25 \mathrm{ppm}$, and 30ppm) and the effect of irradiation time (0 min, $30 \mathrm{~min}, 60 \mathrm{~min}, 90 \mathrm{~min}, 120 \mathrm{~min} 150 \mathrm{~min}$ and $180 \mathrm{~min}$ ). Similarly, we observed the $\mathrm{P} 2-\mathrm{ZnO}$ film catalyst can degrade the maximum amount of MB dye molecules of around $92.4 \%$ within 2 hours 
irradiation in $30 \mathrm{ppm}$ of dye concentration which was higher than the both pristine $\mathrm{ZnO}$ film (63.9\%) and $\mathrm{P} 2-\mathrm{ZnO}(77.6 \%)$ composite catalysts due to the enhanced photosensitizing property by conjugated polymer (P2) to the $\mathrm{ZnO}$ nanoparticles and due to the film formation with a high surface area of $\mathrm{ZnO}$ (ESI Figure S20, table S2, S4, and S6).
The above photocatalytic dye degradation (RhB and MB dyes) experimental results reveal that the conjugated click polymercomposite has acted as a good photosensitizer macromolecule with $\mathrm{ZnO}$ nanoparticles and it can enhance the catalytic ability by making the complete degradation of organic dyes ( $\mathrm{RhB}$ and $\mathrm{MB}$ ) within 3 hours as a film photocatalyst.

Figure 6. Photocatalytic degradation of Rhodamine $\mathrm{B}(\mathrm{RhB})$ dye using $\mathrm{ZnO}, \mathrm{P} 2-\mathrm{ZnO}$ composite, $\mathrm{ZnO}$ film ( $\mathrm{ZnO}$ coated on the glass surface), and $\mathrm{P} 2-\mathrm{ZnO}$ film (composite coated on the glass surface) separately. (A) plot showing the effect of initial concentration, (B) plot showing the effect of irradiation time, (C) Kinetic study plot, and (D) UV Vis spectra of solution after irradiation in different time intervals using P2-ZnO film catalyst (in-setted picture: pictorial images of dye solution before and after $3 \mathrm{hr}$ of irradiation)

2.4.2. Photocatalytic evaluation of $\mathrm{ZnO}$ films ( $\mathrm{ZnO}$ coated on the surface) and "Graft to polymer"-ZnO film [ZnO-coated on polymer-functionalized ("graft to" method) surface]

The influence of the "Graft to" surfaces on photocatalytic degradation of $\mathrm{RhB}$ dye with $\mathrm{ZnO}$ nanoparticles was studied systematically by varying the $\mathrm{ZnO}$ contents and simultaneously comparing with controlled $\mathrm{ZnO}$ films (shown in figure 7). First, we prepared the $\mathrm{ZnO}$ and "Graft to polymer"- $\mathrm{ZnO}$ films by drop-casting the $\mathrm{ZnO}$ nanoparticles with different amounts $(1 \mathrm{mg}, 2 \mathrm{mg}, 3 \mathrm{mg}, 4$ $\mathrm{mg}, 5 \mathrm{mg}$, and $6 \mathrm{mg}$ ) on glass and polymer-functionalized surfaces, respectively. Then the $\mathrm{ZnO}$ films and "Graft to polymer"- $\mathrm{ZnO}$ film surfaces were used as a film photocatalyst in photocatalytic degradation of RhB dye with $10 \mathrm{ppm}$ initial concentration under 2 hours sunlight irradiation. Figure 7A plot showed the removal of dye in terms of percentage after irradiation using $\mathrm{ZnO}$ and "Graft to polymer"-ZnO surfaces with $1 \mathrm{mg}$ to $6 \mathrm{mg}$, and from this plot, we observed there is no significant variation in photocatalytic efficiency with $\mathrm{ZnO}$ and "Graft to polymer"- $\mathrm{ZnO}$ films presumably because in both cases the $\mathrm{ZnO}$ amount was too high causing the prevention of charge transfer (ESI table S7). Consequently, we prepared the films with $\mathrm{ZnO}$ dosage of $0.2 \mathrm{mg}, 0.4 \mathrm{mg}, 0.6 \mathrm{mg}, 0.8 \mathrm{mg}, 1.0 \mathrm{mg}$, and 1.2 $\mathrm{mg}$ and performed the photocatalytic experiment with the same experimental conditions under sunlight. As observed from Figure $7 \mathrm{~B}$, we can see that the catalytic efficiency was slightly different in both catalysts, from $0.6 \mathrm{mg}$ to $1.2 \mathrm{mg}$. But in the case of film 
surfaces with $0.2 \mathrm{mg}$ and $0.4 \mathrm{mg}$ of $\mathrm{ZnO}$ dosage, a large variation in catalytic efficiency was observed (ESI table S8). Further, we again reduced the $\mathrm{ZnO}$ dosages on polymer-functionalized surfaces to optimize the catalytic efficiency. For that, we prepared $\mathrm{ZnO}$ and "Graft to polymer"-ZnO films with $0.05 \mathrm{mg}, 0.1 \mathrm{mg}, 0.15 \mathrm{mg}, 0.20$ $\mathrm{mg}, 0.25 \mathrm{mg}$, and $0.3 \mathrm{mg}$ of $\mathrm{ZnO}$ nanoparticles. As depicted in
Figure 7C, we observed the large variation between $\mathrm{ZnO}$ and "Graft to polymer"- $\mathrm{ZnO}$ film catalyst with $0.15 \mathrm{mg}$ to $0.25 \mathrm{mg}$ of $\mathrm{ZnO}$ in dye degradation. It can be attributed to the change in crystallinity while processing the films (ESI table S9).

Figure 7. Photocatalytic dye degradation using $\mathrm{ZnO}$ films (ZnO-coated on unfunctionalized surface) and "Graft to polymer"-ZnO film [ZnO-coated on polymer-functionalized (graft to method) surface] with varying amount of $\mathrm{ZnO}$ : (A) $1 \mathrm{mg}, 2 \mathrm{mg}, 3 \mathrm{mg}, 4 \mathrm{mg}$, $5 \mathrm{mg}$, and $6 \mathrm{mg}$; (B) $0.2 \mathrm{mg}, 0.4 \mathrm{mg}, 0.6 \mathrm{mg}, 0.8$ $\mathrm{mg}, 1.0 \mathrm{mg}$ and $1.2 \mathrm{mg}$; (C) $0.05 \mathrm{mg}, 0.1 \mathrm{mg}, 0.15 \mathrm{mg}, 0.2 \mathrm{mg}, 0.25 \mathrm{mg}$ and $0.3 \mathrm{mg}$; (D) $0.02 \mathrm{mg}, 0.04 \mathrm{mg}, 0.06 \mathrm{mg}, 0.08 \mathrm{mg}, 0.1 \mathrm{mg}, 0.12 \mathrm{mg}$

Figure 8. Possible Mechanism of photocatalytic dye degradation with P2$\mathrm{ZnO}$ film catalyst

\section{EXPERIMENTAL PART}

\subsection{Raw materials and solvents}

Thiophene-2- carbonitrile, dimethyl succinate, 1-bromododecane, Nbromosuccinimide (NBS), palladium diacetate, ethynyltrimethylsilane, triphenyl phosphine, copper iodide, aniline, hydroquinone, paraformaldehyde, sodium azide, copper(II)sulphate pentahydrate, Rhodamine $\mathrm{B}(\mathrm{RhB})$ dye, dichloromethane, anhydrous THF and anhydrous dimethylformamide (DMF), 2-methyl-2butanol, were purchased from Aldrich chemical company. Silica gel (100-200 mesh), sodiun nitrite, anhydrous sodium sulphate, zinc acetate dihydrate, potassium carbonate $\left(\mathrm{K}_{2} \mathrm{CO}_{3}\right)$ sodium hydroxide, potassium tert-butoxide, hydrochloric acid, hydrobromic acid, acetic acid, petroleum ether, hexane, chloroform, ethanol, and methanol were purchased from Merk India chemical company and used without any further purification. Azidobenzene (compound S7) was synthesized from aniline by following previous literature report ${ }^{15}$. Distilled water was used in all the cases. 


\subsection{Synthesis of monomers:}

The diketopyrrolopyrrole-based dialkynated DADPP monomer (M1) was synthesized using slight modification of method reported in literature and detailed experimental procedure was provided in ESI (as per the reaction scheme S1). In brief, first, (3,6-di(thiophen2-yl)pyrrolo[3,4-c]pyrrole-1,4(2H,5H)-dione) was synthesized from 2-thiophene carbonitrile ${ }^{2}$. Then (3,6-bis(5-bromothiophen-2-yl)-2,5didodecylpyrrolo[3,4-c]pyrrole-1,4(2H,5H)-dione) was reacted with ethynyltrimethylsilane under Sonogashira coupling reaction condition and deprotected with $\mathrm{K}_{2} \mathrm{CO}_{3}$ /methanol to obtain monomer M1 (2,5-didodecyl-3,6-bis(5-ethynylthiophen-2-yl)pyrrolo[3,4c]pyrrole-1,4(2H,5H)-dione $)^{3}$. The diazide AMDDB monomer (1,4bis(azidomethyl)-2,5-bis(dodecyloxy)benzene) (M2) was synthesised from quinol, by slightly modified literature procedure ${ }^{4}$ as shown in ESI reaction scheme $\mathrm{S} 2$.

3.2.1. Model click reaction on DADPP molecule ( 1 in scheme 2$)$ : Synthesis of 2,5-didodecyl-3,6-bis(5-(1-phenyl-1H-1,2,3-triazol-4yl)thiophen-2-yl)pyrrolo[3,4-c]pyrrole-1,4(2H,5H)-dione (compound 1):

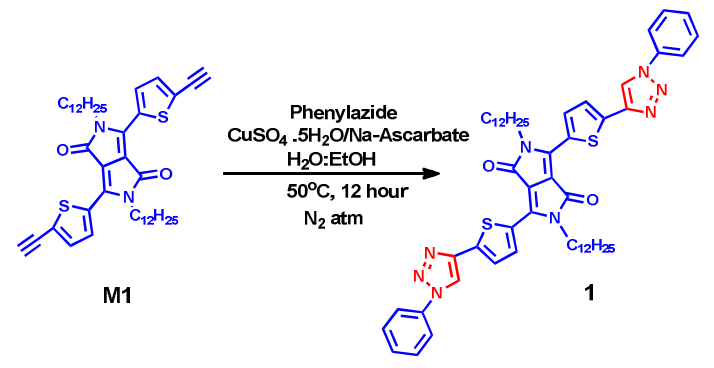

Scheme 2. Synthesis of 2,5-didodecyl-3,6-bis(5-(1-phenyl-1H-1,2,3-triazol4-yl)thiophen-2-yl)pyrrolo[3,4-c]pyrrole-1,4(2H,5H)-dione (1)

Compound M1 (70 mg, $0.102 \mathrm{mmol}$ ), azidobenzene (36 mg, 0.306 $\mathrm{mmol})$, copper(II)sulphate pentahydrate $\left(\mathrm{CuSO}_{4} .5 \mathrm{H}_{2} \mathrm{O}\right)(1.2 \mathrm{mg}$, $0.005 \mathrm{mmol})$, and sodium(L)ascarbate $(2.0 \mathrm{mg}, 0.010 \mathrm{mmol})$ were taken in a $25 \mathrm{ml}$ two-neck round-bottomed flask and added a mixture of solvents ( $5 \mathrm{~mL}$ of water and $5 \mathrm{~mL}$ of ethanol) under $\mathrm{N}_{2}$ atm. The reaction mixture was heated up to $50^{\circ} \mathrm{C}$ for 22 hours under $\mathrm{N}_{2}$ atm. Then the reaction mass was quenched with saturated ammonium chloride solution and extracted with $100 \mathrm{~mL}$ of chloroform (two times). Then chloroform layer was separated, passed through anhydrous sodium sulphate. Solvent was removed by a rotary evaporator. The crude solid was purified by coloumn chromatography using $50 \%$ chloroform in hexane. Finally, we obtained a purple red color solid $(70 \mathrm{mg}, 75 \%)^{5}$. ${ }^{1} \mathrm{H} \mathrm{NMR}\left(\mathrm{CDCl}_{3}\right.$, $400 \mathrm{MHz}$ ) Chemical shift in ppm: 9.05 (d, 2H, Ar-H (thiophene) $\mathrm{J}=4.1 \mathrm{~Hz}), 8.24(\mathrm{~s}, 2 \mathrm{H}$, triazole ring $\mathrm{C}-\mathrm{H}), 7.79(\mathrm{~d}, 2 \mathrm{H} \mathrm{Ar}-\mathrm{H}$ (thiophene) $\mathrm{J}=8.0 \mathrm{~Hz}$ ) 7.77 (t, 4H, Ar-H (phenyl)), 7.57-7.50 (m, 6H, Ar-H (phenyl)), 4.15 (t, 4H, N-C $\left.\underline{H}_{2}\right), 1.78$ (m, 4H, N-CH $\left.{ }_{2}-\underline{C}_{2}\right)$, $1.46\left(\mathrm{~m}, 4 \mathrm{H}, \mathrm{N}-\underline{C}_{2}-\mathrm{CH}_{2}-\mathrm{CH}_{2}\right), 1.36-1.22\left(\mathrm{~m}, 32 \mathrm{H}, \mathrm{n}-\underline{\mathrm{C}}_{2}\right)$, and 0.86 (t, $\left.6 \mathrm{H}, \mathrm{CH}_{2}-\underline{\mathrm{C}}_{3}\right)$ ppm. ${ }^{13} \mathrm{C} \mathrm{NMR}\left(\mathrm{CDCl}_{3}, 100.64 \mathrm{MHz}\right)$ Chemical shift in ppm: 161.32, 142.55, 139.53, 137.82, 136.37, $129.92,129.33,129.21,125.63,118.01,109.62,108.27,76.71$, $42.38,37.9,31.92,30.15,29.71,29.63,29.51,29.56,29.36,26.96$, 22.69, and $14.1 \mathrm{ppm}$. FT-IR (KBr) Stretching frequency: 3305, $3050,2920,2850,2140$, and $1663 \mathrm{~cm}^{-1}$.

\subsection{Click polymerization}

\subsubsection{Synthesis of click polymerP1:}

In a clean and dry $25 \mathrm{~mL}$ double-neck round bottom flask under a nitrogen atmosphere, the compound M1 (0.292 mmol) and M2 (0.292 mmol) was dissolved in anhydrous tetrahydrofuran. The reaction mixture was again degassed with $\mathrm{N}_{2}$ gas. Then $5 \mathrm{~mol} \%$ of $\mathrm{CuI}$ and $0.2 \mathrm{~mL}$ distilled diisopropylamine was dissolved into the small vial and degassed with $\mathrm{N}_{2}$ gas. After 5 mins this solution becomes a yellowish-green color. This solution was charged into the reaction mass in one portion. Then heating was started and the reaction condition was maintained at $50^{\circ} \mathrm{C}$ for 72 hours. After 72 hours violet color reaction mass was obtained. The solvent was removed using a vacuum and charged $100 \mathrm{~mL}$ of chloroform. The chloroform layer was washed with saturated ammonium chloride and water two times. Finally, the organic layer was separated and distilled out of the solvent. The solid was reprecipitated with a chloroform-methanol mixture. The click polymer P1was purified by soxhlet extraction using methanol, acetone, diethyl ether, and chloroform sequentially. Pure polymers were obtained from the chloroform layer. ${ }^{1} \mathrm{H}$ NMR $\left(\mathrm{CDCl}_{3}, 400 \mathrm{MHz}\right.$,) Chemical shift in ppm: 9.04-8.81 (broad, 2H, Ar-H (thiophene)), 7.77-7.68 (broad, 1H, triazole-H), 7.40-7.25 (broad, 2H, Ar-H (thiophene)), 6.85-6.70 (broad, 2H, Ar-H (phenyl)), 5.58-5.40 (broad, 4H, benzyl-H), 4.103.75 (broad, $\left.8 \mathrm{H}, \mathrm{N}-\underline{\mathrm{C}}_{2}\right), 1.82-0.60\left(\mathrm{n}-\mathrm{CH}_{2}\right.$ and $\mathrm{CH}_{3}$ group of alkyl chains) ppm. FT-IR (KBr) Stretching frequency: 3070, 2938 and $1657 \mathrm{~cm}^{-1}$.GPC; Mn value of P1 is 7435 .

\subsubsection{Synthesis of click polymer $P 2$ :}

In a cleaned and dry $25 \mathrm{~mL}$ two neck round bottom flask, monomers M1 $(0.292 \mathrm{mmol})$ and M2 $(0.292 \mathrm{mmol})$ were taken and added 5 mol\% of $\mathrm{Cu}(\mathrm{II}) \mathrm{SO}_{4} .5 \mathrm{H}_{2} \mathrm{O}$, Na-ascorbate (5 mol\%), distilled diisopropylamine $(0.2 \mathrm{~mL})$, and anhydrous tetrahydrofuran $(5 \mathrm{~mL})$. Again, the reaction mixture was degassed with $\mathrm{N}_{2}$ gas. The reaction mixture was heated at $50^{\circ} \mathrm{C}$ and maintained the reaction condition for 48 hours in the $\mathrm{N}_{2}$ atmosphere. Visual changes of the reaction mass color from red to violet-red, along with an indication of viscosity increase was also observed. After completion of the reaction, the solvent was removed under vacuum and charged 100 $\mathrm{mL}$ of chloroform into the reaction mixture followed by washing with saturated ammonium chloride solution and water two times. The organic layer was separated out and passed through the anhydrous sodium sulphate. The solvent was distilled out and the crude solid was purified by reprecipitation with a chloroformmethanol mixture. The polymers P2 was further purified by the soxhlet extraction method sequentially by different solvents (methanol, acetone, diethyl ether, and finally chloroform). Finally, pure polymer $\mathrm{P} 2$ was obtained from the chloroform fraction. ${ }^{1} \mathrm{H}$ NMR $\left(\mathrm{CDCl}_{3}, 400 \mathrm{MHz}\right)$ Chemical shift values in ppm: $8.97(2 \mathrm{H}$, Ar-H (thiophene)), $7.82(1 \mathrm{H}$, triazole ring $\mathrm{C}-\mathrm{H}), 7.41(2 \mathrm{H}, \mathrm{Ar}-\mathrm{H}$ (thiophene)), $6.90(2 \mathrm{H}$, Ar- $\mathrm{H}$ (phenyl)), 5.54 (4H, benzyl-H) 4.23$4.10\left(4 \mathrm{H}, \mathrm{N}-\underline{\mathrm{C}}_{2}\right)$, 4.05-3.91 (4H, O-C $\left.\underline{\mathrm{H}}_{2}\right), 1.75-0.69\left(\mathrm{CH}_{2}\right.$ and $\mathrm{CH}_{3}$ groups in aliphatic chains) ppm. FT-IR (KBr) Stretching frequency: 3080,2920 and $1650 \mathrm{~cm}^{-1}$. GPC; $\mathrm{M}_{\mathrm{n}}$ value for P2 polymer is 5967.

\subsection{Functionalization of surfaces with click polymers (Graft To approach) on self-assembled monolayer (SAM) of azide:}


In a $100 \mathrm{~mL}$ single neck flask, under $\mathrm{N}_{2}$ atmosphere, azidefunctionalized glass surfaces ( 5 number), $5 \mathrm{mg}$ of click polymer (P2), and $7.5 \mathrm{~mL}$ of anhydrous tetrahydrofuran were taken. Then 1 $\mathrm{mg}$ of $\mathrm{CuI}, 0.02 \mathrm{~mL}$ distilled diisopropylamine, and $2.5 \mathrm{~mL}$ of anhydrous DMF were added into the small vial and degassed with $\mathrm{N}_{2}$ gas. After 5 mins this solution becomes a yellowish-green color. This solution was charged into the reaction mass in one portion and heated for 2 hours under reflux conditions. Then it was cooled to room temperature and ultrasonicated by 10 mins. Finally, polymer functionalized glass surfaces were washed several times with tetrahydrofuran and dried at $50^{\circ} \mathrm{C}$ under vacuum for 2 hours. These polymer-functionalized glass surfaces were stored in desiccators ${ }^{12}$.

\subsection{Preparation of drop-casted surfaces with polymer}

We dissolved $1 \mathrm{mg}$ of click polymer (P2) in $10 \mathrm{~mL}$ of chloroform to prepare a polymer stock solution (100 ppm concentration). Then $20 \mu \mathrm{L}$ of polymer solution were drop casted on the glass slides (square slides $2.5 \mathrm{~cm} \times 2.5 \mathrm{~cm}$ ) at $50{ }^{\circ} \mathrm{C}$. The resulting drop-casted polymer surfaces (it containing $2 \mu \mathrm{g}$ of click polymer) were dried at $50^{\circ} \mathrm{C}$ for 6 hours and it was used for further surface characterization studies as a control sample.

\subsection{Preparation of $\mathrm{P} 2-\mathrm{ZnO}$ composite}

The polymer- $\mathrm{ZnO}$ composite $(\mathrm{P} 2-\mathrm{ZnO})$ was prepared by using a previously reported procedure. Initially, we prepared a dispersed solution of $\mathrm{ZnO}$ (495 mg of $\mathrm{ZnO}$ in $100 \mathrm{~mL}$ of methanol) with half an hour of sonication. Meanwhile, we prepared the click polymer solution by dissolving $5 \mathrm{mg}$ of polymer in $5 \mathrm{~mL}$ of chloroform. Then the polymer solution was added drop-wise into $\mathrm{ZnO}$ dispersed solution and the mixture was maintained under stirring conditions for 1 hour at ambient temperature. Then the solvents were removed by a rotary evaporator. Finally, we got $\mathrm{P} 2-\mathrm{ZnO}$ composite material (485mg, purple color solid) after drying at $110{ }^{\circ} \mathrm{C}$ for 12 hours. These composite materials were used for photocatalytic experiments directly ${ }^{14}$.

\subsection{Preparation of unfunctionalized surfaces coated with $\mathrm{ZnO}$ and unfunctionalized surfaces coated with $\mathrm{P2}-\mathrm{ZnO}$ composite}

We prepared the $\mathrm{ZnO}$-coated surfaces with different amounts of $\mathrm{ZnO}$ nanoparticles by drop-casting on glass surfaces for control experiments. Initially, we took $5 \mathrm{mg}$ of $\mathrm{ZnO}$ nanoparticles in a vial and made a dispersed solution with $2.5 \mathrm{~mL}$ of ethanol. Then the dispersed $\mathrm{ZnO}$ solution was drop-casted on the glass surfaces at 90 ${ }^{\circ} \mathrm{C}$. The $\mathrm{ZnO}$ film was dried at $110^{\circ} \mathrm{C}$ for 12 hours before being used in a photocatalytic experiment. For preparing the P2-ZnO-coated surface, we measured $5 \mathrm{mg}$ of $\mathrm{P} 2-\mathrm{ZnO}$ composite and made the dispersed solution in $2.5 \mathrm{~mL}$ of ethanol. Then the dispersed $\mathrm{P} 2-\mathrm{ZnO}$ solution was drop cast on the glass slides. The resulting P2-ZnO film was dried at $110^{\circ} \mathrm{C}$ for 12 hours before use.

3.8. Preparation of $\mathrm{ZnO}$ films (ZnO-coated on unfunctionalized surface) and "Graft to polymer"- ZnO films [ZnO-coated on polymerfunctionalized (graft to method) surface]
We prepared $\mathrm{ZnO}$ films and "Graft to polymer"- $\mathrm{ZnO}$ films with different amounts of $\mathrm{ZnO}$ nanoparticles on "Graft to polymer" surfaces [polymer-functionalized surfaces] by drop casting method. For that we prepared two set of $\mathrm{ZnO}$ dispersed solution with different weights like (i) $0.02 \mathrm{mg}, 0.04 \mathrm{mg}, 0.06 \mathrm{mg}, 0.08 \mathrm{mg}, 0.1$ $\mathrm{mg}, 0.12 \mathrm{mg}$, (ii) $0.05 \mathrm{mg}, 0.1 \mathrm{mg}, 0.15 \mathrm{mg}, 0.2 \mathrm{mg}, 0.25 \mathrm{mg}, 0.3$ $\mathrm{mg}$, (iii) $0.2 \mathrm{mg}, 0.4 \mathrm{mg}, 0.6 \mathrm{mg}, 0.8 \mathrm{mg}, 1.0 \mathrm{mg}, 1.2 \mathrm{mg}$, (iv) $1 \mathrm{mg}$, $2 \mathrm{mg}, 3 \mathrm{mg}, 4 \mathrm{mg}, 5 \mathrm{mg}$, and $6 \mathrm{mg}$. Then the dispersed solutions were drop casted on glass surfaces and polymer-functionalized surfaces at $90^{\circ} \mathrm{C}$ to get the $\mathrm{ZnO}$ and 'Graft to polymer- $\mathrm{ZnO}$ films respectively. Finally, the films were dried at $110^{\circ} \mathrm{C}$ for 12 hours.

\section{CONCLUSIONS}

Diketopyrrolopyrrole-based triazole-linked "click" polymers were synthesized successfully using two different copper-based catalysts. Computational models and theoretical calculations predicted localized HOMO, LUMO, and fairly low band gaps between the energy levels. Further, self-assembled monolayer (SAM) formation followed by the "graft to" method of immobilization was used successfully to immobilize those polymers to surfaces ("Graft to polymer" surfaces). Fluorescence microscopy, atomic force microscopy (AFM), scanning electron microscopy and other analysis confirmed a denser and more regular surface coverage when SAM formation followed by graft to techniques were used rather than conventional drop-casting technique. This was further confirmed from the calculations of grafting density using XPS and other techniques. Finally, the surfaces in combination with $\mathrm{ZnO}$ nanoparticles have been used as third-generation photocatalytic chips for the degradation of polluting dyes.

\section{ACKNOWLEDGEMENTS}

Financial support from DST project (ECR/2015/000219) and CSIR-CLRI in house project MLP13 is gratefully acknowledged. CSIR-CLRI communication Number is 1610.

\section{Electronic Supporting Information}

Detailed experimental procedures and NMR spectral data for the monomers and surfaces functionalization were provided in ESI. The Characterization of ZnO-based photocatalysts, and the detailed experimental procedure of photocatalytic dye degradation studies also were available in ESI.

\section{Author Information (Email address)}

*Debasis Samanta: debasis@clri.res.in Phone: +91-44 24437189. Fax: +91-44-24911589;

Periyamuthu Ramar: ppramar93@gmail.com

Venkatraman Raghavendra: raghav011986@gmail.com

\section{Orcid ID}

*DebasisSamanta: 0000-0002-3043-8033

Periyamuthu Ramar: 0000-0002-2786-9502

Notes: The authors declare no competing financial interest. 


\section{REFERENCE}

1 N. Serpone and A. V. Emeline, J. Phys. Chem. Lett., 29 2012, 3, 673.

2 L. Jiang, M. Xu, S. Jiang, P.-L. Tremblay, and T. Zhang, Cellulose, 2022, 29, 175.

3 S. Sarkar, N. T. Ponce, A. Banerjee, R. Bandopadhyay, S. Rajendran, and E. Lichtfouse, Environ. Chem. Lett., 2020, 18, 1569.

4 X. Chen, S. Shen, L. Guo, and S. S. Mao, Chem. Rev. 2010, 110, 6503.

5 B. Kraeutler and A. J. Bard, J. Am. Chem. Soc., 1978, 100, 2239. Z. Mohammed Redha, H. Abdulla Yusuf, R. Amin, and M. Bououdina, Arab. J. Basic Appl. Sci, 2020, 27, 287. Y.-H. Chang, S.-R. Tseng, C.-Y. Chen, H.-F. Meng, E.C. Chen, S.-F. Horng, and C.-S. Hsu, Org. Electron. 2009, 10, 741. B. H. Lee, S. H. Park, H. Back, and K. Lee, Adv. Funct. Mat., 2011, 21, 487.

A Kaliyaraj Selva Kumar, Y. Zhang, D. Li, and R. G. Compton, Electrochem. commun., 2020, 121, 106867.

. Danglad-Flores, S. Eickelmann, and H. Riegler, Chem. Eng. Sci., 2018, 179, 257.

F. C. W., R. V., D. M. M., P. R. F. W., H. W. D., M. R D., and R. J. F., Science, 1996, 273, 912.

J. Zhang, D. P. Burt, A. L. Whitworth, D. Mandler, and P. R. Unwin, Phys. Chem. Chem. Phys., 2009, 11, 3490. M. Breton, J. Macromol. Sci. part C null, 1981, 21, 61.

P. Paoprasert, J. W. Spalenka, D. L. Peterson, R. E. Ruther, R. J. Hamers, P. G. Evans, and P. Gopalan, J. Mater. Chem., 2010, 20, 2651.

D. Samanta and A. Sarkar, Chem. Soc. Rev., 2011, 40, 2567.

P. Murugan, M. Krishnamurthy, S. N. Jaisankar, D. Samanta, and A. B. Mandal, Chem. Soc. Rev., 2015, 44, 3212.

L. Yang, S. K. Sontag, T. W. LaJoie, W. Li, N. E. Huddleston, J. Locklin, and W. You, ACS Appl. Mater. Interfaces, 2012, 4, 5069.

J.-M. Chiu and Y. Tai, ACS Appl. Mater. Interfaces, 2013, 5, 6946

Z. A. Page, B. Narupai, C. W. Pester, R. Bou Zerdan, A. Sokolov, D. S. Laitar, S. Mukhopadhyay, S. Sprague, A. J. McGrath, J. W. Kramer, P. Trefonas, and C. J. Hawker, ACS Cent. Sci., 2017, 3, 654.

A. Punzi, E. Maiorano, F. Nicoletta, D. Blasi, A. Ardizzone, N. Ventosa, I. Ratera, J. Veciana, and G. M. Farinola, Eur. J. Org. Chem., 2016, 2016, 2617.

D. Samanta, P. Murugan, S. J. Ananthakrishnan, N. Somanathan, S. K. Das, S. N. Jaisankar, and A. B. Mandal, Chem. Commun., 2012, 48, 12068.

Z. Qiu, B. A. G. Hammer, and K. MÃ¹/4len, Progress in Polymer Science, 2020, 100, 101179.

A. Qin, J. W. Y. Lam, and B. Z. Tang, Chem. Soc. Rev., 2010, 39, 2522.

B. Yan, Y. Wang, X. Jiang, K. Liu, and L. Guo, ACS Appl. Mater. Interfaces, 2017, 9, 29113.

Y. Wang, Y.-Z. Zheng, S. Lu, X. Tao, Y. Che, and J.-F. Chen, ACS Appl. Mater. Interfaces, 2015, 7, 6093.

P. Murugan, P. Ramar, A. B. Mandal, and D. Samanta, ChemistrySelect, 2019, 4, 14214.

H. Anwer, A. Mahmood, J. Lee, K.-H. Kim, J.-W. Park, and A. C. K. Yip, Nano Res., 2019, 12, 955.

L. Huo, J. Hou, H.-Y. Chen, S. Zhang, Y. Jiang, T. L. Chen, and Y. Yang, Macromolecules, 2009, 42, 6564.

W. A. Braunecker, S. D. Oosterhout, Z. R. Owczarczyk, R. E. Larsen, B. W. Larson, D. S. Ginley, O. V. Boltalina, S. H. Strauss, N. Kopidakis, and D. C. Olson, Macromolecules, 2013, 46, 3367.

S. Sampath, A. A. Boopathi, and A. B. Mandal, Phys. Chem. Chem. Phys., 2016, 18, 21251.

31 W. Sun, S. Zhou, B. You, and L. Wu, Macromolecules, 2013, 46, 7018.

X. Yang, B. Shen, Y. Jiang, Z. Zhao, C. Wang, C. Ma, B. Yang, and Q. Lin, J. Mater. Chem. A, 2013, 1, 1201.

33 M. Dubner, N. D. Spencer, and C. Padeste, Langmuir, 2014, 30, 14971.

34 R. Sen, D. Gahtory, R. R. Carvalho, B. Albada, F. L. v. Delft, and H. Zuilhof, Angew. Chem. Int. Ed., 2017, 56, 4130.

35 F. Ekiz, F. Ouzkaya, M. Akin, S. Timur, C. Tanyeli, and L. Toppare, J. Mater. Chem., 2011, 21, 12337.

36 Q. Niu, K. Gao, Z. Lin, and W. Wu, Chem. Commun., $2013,49,9137$.

37 M. E. Welch, N. L. Ritzert, H. Chen, N. L. Smith, M. E. Tague, Y. Xu, B. A. Baird, H. D. Abrua, and C. K. Ober, J. Am. Chem. Soc., 2014, 136, 1879. 